\title{
Shadow Economy in Russia
}

Fakhrutdinova E.V.a

Fakhrutdinov R.M. ${ }^{b}$

Kolesnikova J.S. ${ }^{c}$

Yagudin R.H. ${ }^{d}$

\author{
ac Kazan Federal University, Institute of Management, Economics and Finance, Kazan, 420008, Russia \\ Email: hulia_k@mail.ru \\ ${ }^{b}$ Graduate School of Management is St. Petersburg State University, Volkhovskiy Per.3 St.Petersburg 199004, Russia \\ ${ }^{d}$ Republican Clinical Hospital, 420064, Kazan, Orenburg tract, 138, Russia
}

\section{Doi:10.5901/mjss.2015.v6n1s3p67}

\section{Abstract}

Importance of the problem is defined by a solid size of shadow component of the economy both nationally and globally, suggesting that an in-depth study of the basic principles, framework and content of informal economic activity in our country, taking into account the current trends to combat it worldwide and to bear in mind its impact when it comes to building a stable state of strategic management model with respect to business entities. In order to understand the grounds of communication between formal and informal sectors occurs the need to conduct a thorough study of the phenomenon of illegal economy in the current transition of the market, its importance in reproductive economic processes and elements of its functioning. This paper is aimed to show the essence of the shadow economy and to know the consequences of activity in the shade.

Keywords: shadow economy, informal sector, tax evasion, crime, gross domestic product.

\section{Introduction}

The relevance of this article is explained by the risen problem - in our time there is a presence of almost two full orders of business in Russian Federation: legal, which operates according to the official laws of the country and illegal (or on the verge of the law), which operates in a situation of non-compliance with laws, not recognizing the accepted system of revenue and depriving the authorities of the country the opportunity to participate in their distribution.

Shadow economic activity takes place in absolutely all countries of the world, and the political system is not so important as well as the standards of living and other socio-economic conditions. According to the World Bank in 2013 (Figure1), the average international level of shadow economic activity was equal to $17.2 \%$ of the GDP of the country, but this figure varies vastly. As an example, the minimum index of the shadow economy presence is in Switzerland - $8.4 \%$ of GDP, in China - $12.7 \%$, in Russia - $43.8 \%$ and the highest level of shadow economy takes place in Bolivia - $66.4 \%$ of GDP [13]. National governments of various countries strive by all means affect the size of the illegal component of the economy, while cycling methods ranging from tougher sanctions for financial crimes, ending up to stimulate "a conscientious self-consciousness" of citizens [2]. Here is the chart of shadow part presence of some developed countries.

Table 1: Shadow economy in the world 2013 ([13] and elaborated by author)

\begin{tabular}{|l|c|c|c|c|c|c|c|c|c|c|}
\hline Country & USA & Japan & UK & China & France & Germany & Spain & Italy & Brasil & Russia \\
\hline Shadow Economy ofGDP, $\%$ & $8.6 \%$ & $11.0 \%$ & $12.5 \%$ & $12.7 \%$ & $15.0 \%$ & $16.0 \%$ & $22.5 \%$ & $27.0 \%$ & $34.4 \%$ & $43.8 \%$ \\
\hline
\end{tabular}

\section{Method}

In the current situation of our country it is impossible not take into account the fact that the shadow economy has a significant share of the country's GDP, and a fairly long time, it does not lose its position. In the situation of the search of new methods for improving the economic condition of Russia and the establishment of sustainable growth, it is necessary 
to conduct a comprehensive analysis of the informal economy, considering it as a full-fledged member of the modern economy.

Despite the presence of the positive directions in Russian economy and in policing bodies, the situation in the national economic and fiscal areas remains difficult and is characterized by an increase in the tax and financial crime rate in absolutely all basic sectors of the national economy, its massive and highest stage of latency, continuous complexity of the techniques used to avoid taxation, including those based on the imperfect functioning of the legislation. All of the above provides the basis that gives the right to assume the current process of transition of economic entities into the shade as the emergence of the threat of the state's economic stability and explains the need for the study of this phenomenon [7].

As a base for the analysis of "dirty" money sources, we have chosen the structure of the shadow economy proposed in the methodology for assessing the shadow economy according to the System of National Accounts, developed and recommended by the United Nations Statistical Commission in 1993[1]. Based on this approach, we can construct a model that describes the productive economic activities depending on their belonging to shadow or legal economy. As a result, we got four conditional sectors of the economy, which can be seen as sphere of education revenues.

First sector - contains permitted lawful activities, and subjects them performing shall report to the state authorities in the specific dates and in procedure provided by law, and which can be further tested if necessary.

The second sector - is an activity permitted by law and implemented by local organizations officially, but the dimensions of which are hidden or resplendence in order to evade the payment of taxes and mandatory social payments or to perform other administrative obligations.

The third sector - is the activity of unincorporated (belonging to one owner - often family) enterprises working for their own needs, i.e. production of goods and services made in the household and consumed by them, as well as the activities of unincorporated enterprises with informal employment (temporary team of builders, etc.).

Fourth sector - is activity directly prohibited by the law, aimed at the production and distribution of goods and services for which there is an effective market demand (production and distribution of drugs, prostitution, smuggling).

In the transitional socio-economic systems, the importance of the non-observed economy is much diversified. From one perspective, tax evasion increases the competitive advantage of companies using work in the shadows, gives you the opportunity to derive additional income to their employees and, among other things, reduces the level of the official unemployment [5]. However, if you look from a different angle, illegal economic activity causes damage to the treasury, by several times lowers the results of all the efforts of macroeconomic policy, rejects interest from all sorts of possible investors, creates an unfavourable situation of law-abiding citizens and taxpayers and causes harm to the public interests of the country (Figure 1).

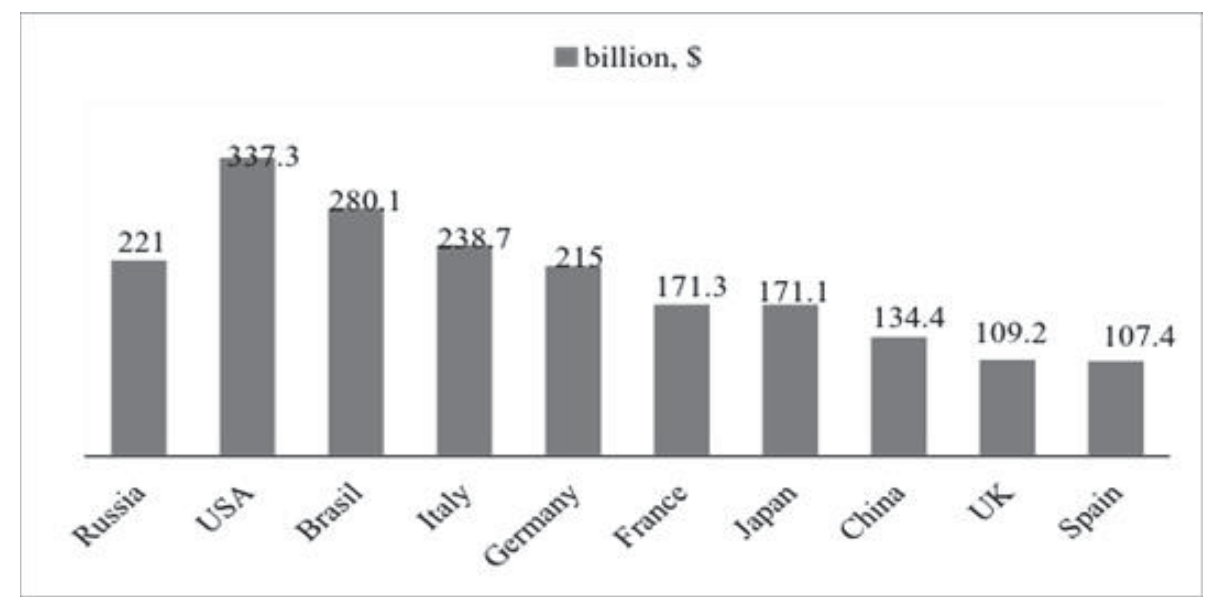

Fig. 1. Amount of non-received taxes ([13] and elaborated by author).

\section{Results}

In a general sense, the overall level of investigation of this problem makes it impossible to systematically demonstrate the characteristics of the shadow component as part of the economy and the directions and methods of a multilateral 
approach to the solution of the main difficulties. However, having avoided these problems, it is still impossible to convincingly move towards establishing a functioning market mechanism in Russia. Plus, the impact of the illegal economy that improves the welfare of the population is still really uncertain [5]. Most of the scientists focus mainly on the negative aspects of the illegal economy; a significant number of scientists confirm its positive impact on economic growth under specific circumstances. The shadow economy is not always carries destructive properties. Sometimes retreat into shadow allows you to adjust the economic processes of the formal economy. Below are some of these properties [4]:

1. "Glue" of the economy - easing crisis periods in the formal economy - prevents standstill of resources, leading them into the shade for a while, and then taking them back to the light at the end of the crisis period.

2. Integrated controller - using it comes the solution of various critical problems of the company, which is problematic to decide officially.

3. "Spring" of employment - an example of forced Fade for human survival, or a similar picture, but on the other underlying reason - implementation abilities and disclosure of entrepreneur talent of people who were unable to express themselves in formal structures [10].

4. Functional aspect - saves the progress of the economy in the transition period of not yet fully established market economy.

5. "Piston" of economic activity - money earned in the shadows, but spent in the formal economy, is deemed to be for the benefit of it, thereby creating the conditions for further development.

However, keeping in mind the fact that everything in this world is dual, the shadow economy has a number of aspects that put the economy and the whole country in danger [6]:

1. Unequal welfare of society because of the corruption of some group of people (government officials, criminals) [14].

2. Distortion of the tax system - a departure from the taxation introduces an additional burden on law-abiding citizens, which leads to more people moving into the shade, in order to circumvent the tax system - a vicious circle.

3. Disorder of the formal process of reproduction - as an example, this aspect of the illegal economy does not bear the idea of a strict control over the personnel, which leads to a decrease in qualification and motivation of the latter - the result is the production, which has a lower value compared to a similar product, issued an official supervision [11].

4. Aspect of improving competitiveness of the economy - transfer of production factors into shade and decline in investment activity together gives a lower gross domestic product.

5. Aspect of high entry barriers to the market - a consequence of corruption in the higher echelons of power, the role of a meager legislative leverage - the competition in the official markets insignificant: either there are monopolies or cartels.

6. Aspect of rising crime in society - as the shadow economy is not regulated by law and other regulations, then in conflict resolution no one will be no recourse to the law, and therefore can start a sad picture of the division of property through racketeering, armed clashes and so on.

7. Aspect of reducing morality of society - someone in the shade makes decent fortune, but still goes unpunished, and someone regularly pays taxes and barely making one's ends meet. It sounds tempting, while increasing these kinds of thoughts in society, economy, in the first place, will receive a very hard hit in the future.

8. Vulnerability of the poor and disabled members of society - the more people does not pay taxes, the smaller the scale of social programs of the state [8].

9. Aspect of disproportionate development of the economy - investments in sectors that are in the shadow, give a greater return on them. The downside is the rapid development of this sector, which may go against the state strategy of the country development in the long term.

Shadow economy can be most easily stylized by a pyramid. Form of a pyramid is picked up deliberately: on the one hand, it preserves the principle of subordination (compliance of vertical subordination of "lower" layers to "higher" ones) interaction among the illegal economy; on the other hand, it clearly describes the approximate number of people in every layer of the pyramid.

The pyramid is composed of three layers, the main layer - the region of the tip of the pyramid. There is no doubt that for any meso-, micro-and macro-level government staff essence of the pyramid is not constant.

In a single embodiment, a figure subject of illegal economy is shown by researcher in the field of illegal Russian economy - Y. Latov (see Fig. 2). 


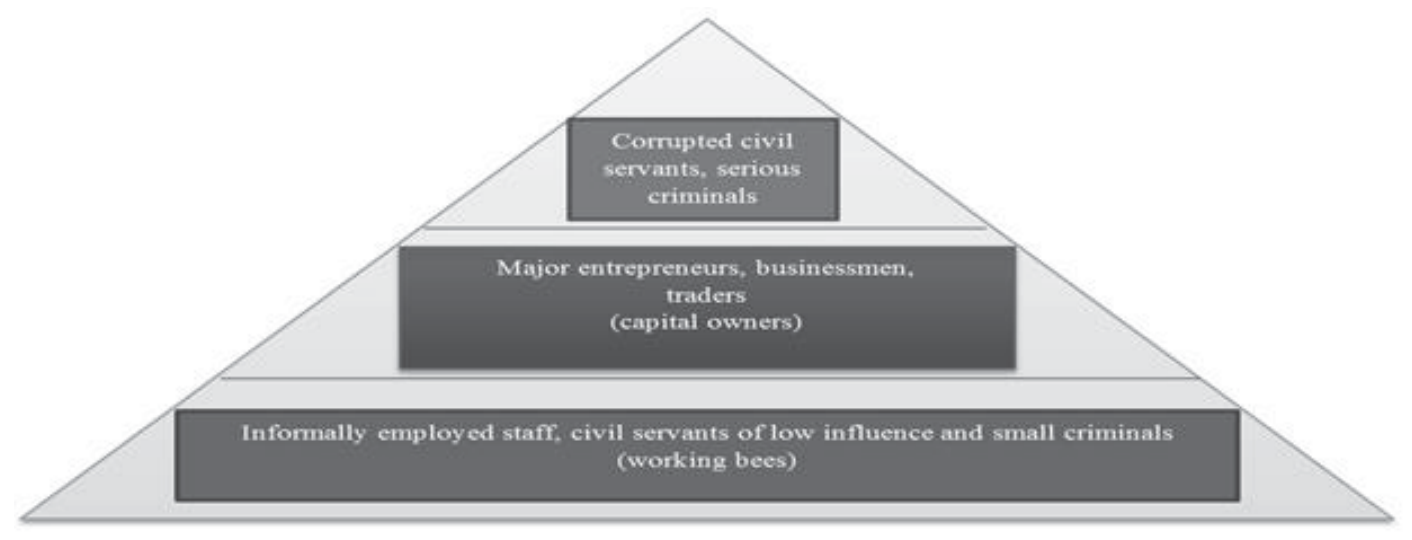

Fig.2. Subjects of shadow economy [9].

The top of the pyramid is formed by: 1) the important persons of the government, and besides them serving as a base environment of persons representing the legislative bodies, the main persons of judicial, investigative, fiscal institutions holding these powers to adopt the necessary decisions or acts; 2) financial and industrial fixed assets - physical and legal entities with funds proportional to the amount of funds to micro and mesolevel; 3) organized criminal association - criminal businessmen, on the one hand, represented by residents of a solid business, and on the other - the criminal environment; 4) power-hierarchical institution of the Orthodox Church - the largest owner of property with a very large accumulation of money available, shut off from the government intervention.

The middle sector is formed by traders, entrepreneurs, financiers and industrialists. This circle of people is associated with one goal - the desire and the chance to denote them as the base of the middle class of the state with a standard market economy. This class can also enroll "medium" (according to the degree of influence) civil servants, criminal units, which use their own place in the hierarchy in their own mercantile purposes.

Possible helpers of medial shadow businesses layer of our pyramid, in my opinion, are the large number of persons of the last layer - the base of the pyramid, displayed with employed workers, petty civil servants and small criminals.

Symbolic expression of the structure of shadow schemes and its hierarchy has the opportunity to be a given sequence: a bureaucrat of higher power apparatus, the capitalist mogul, criminal entity, businessman, hire workers. Such a construction is similar to the configuration of the ordinary and economically productive activities (omitted only criminal components). This is explained by the fact that a significant part of the population of our country is active in the informal sector [15].

The harm caused to the country and the society with the top two layers of the pyramid subjects of the illegal economy, cannot be compared with loss of the economy, which can be obtained from the activities of the subjects of the base of the pyramid. The problem is, by no means, not only in the size of the total loss. Corrupt officials, for example, destroy the basic principles of statehood [3].

Labor market is also affected by the activities of shadow economy. Firstly, it distorts the structure of employment nearly $25 \%$ of economically active people are not offered or don't want to sign the official labor contract, which makes this number up to 10 million people in Russia (see Fig. 3). 


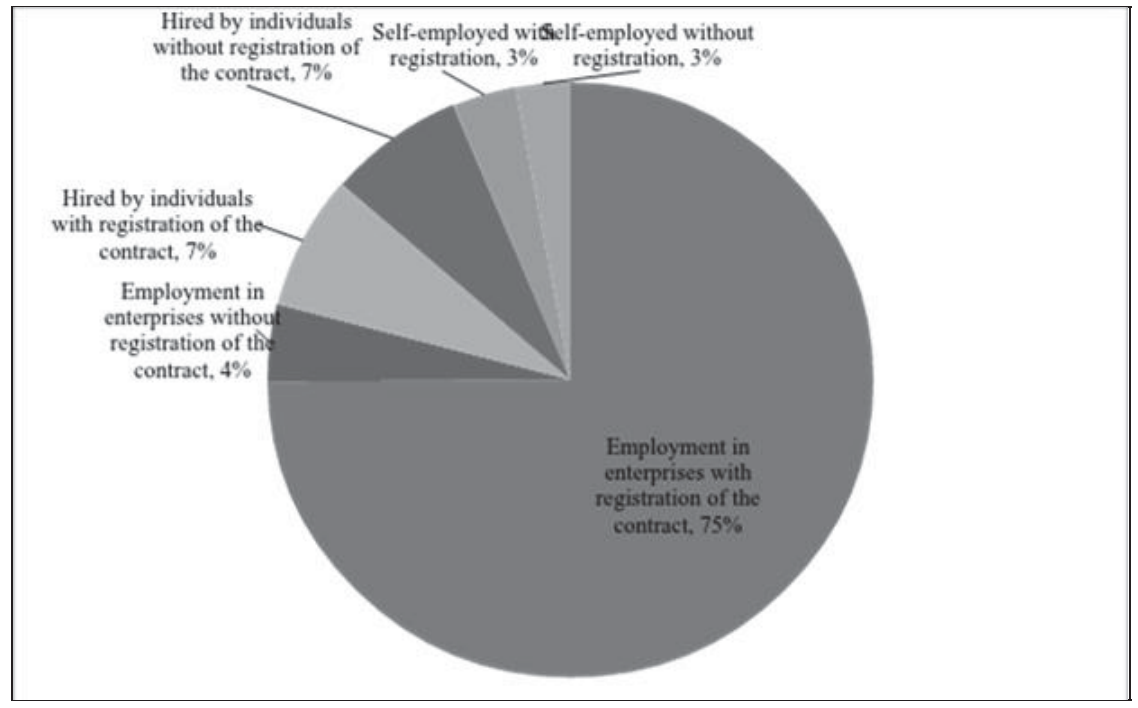

Fig. 3. Structure of Employment in Russia ([12] and elaborated by author).

Deeper analysis of the labor market situation gives us a possibility to divide those who work unofficially into directions of their activity. Results turned up not as a surprise: most of them work in trade, agriculture and construction activities (see Fig.4).

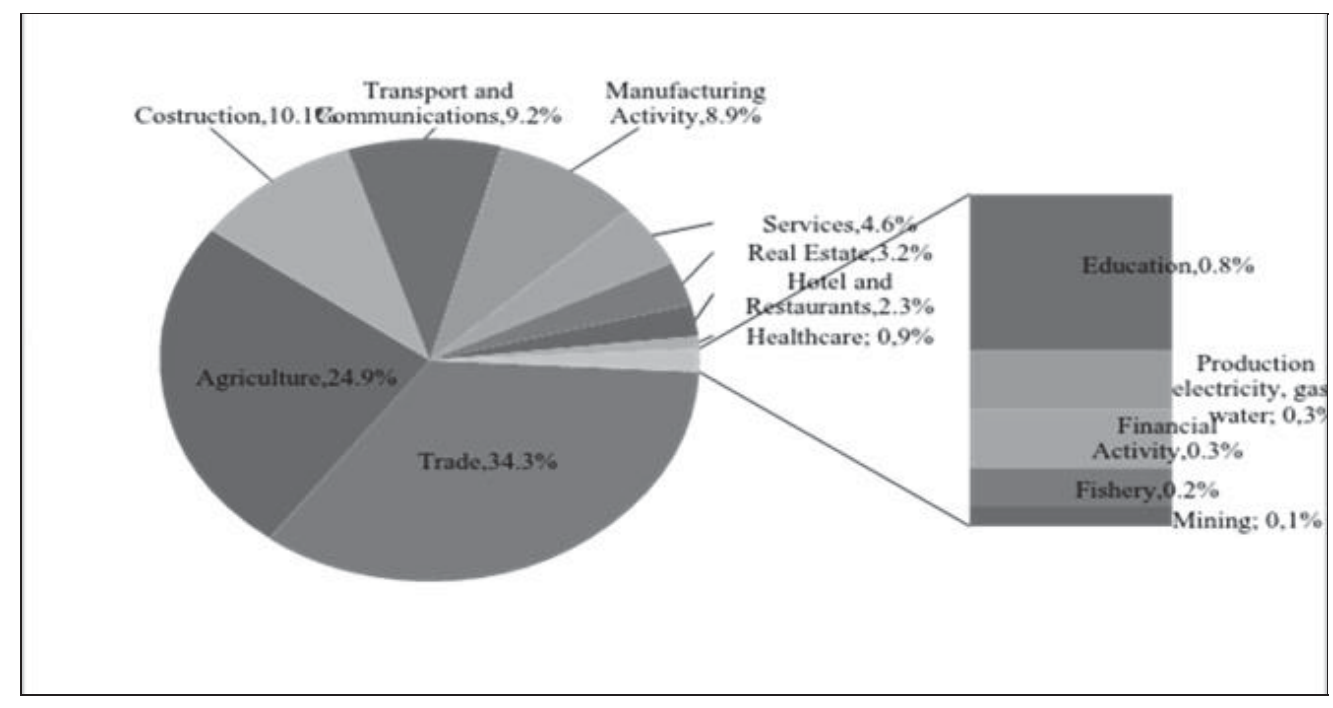

Fig. 4. Areas with informally employed ([12] and elaborated by author).

\section{Conclusion}

According to this paper we can formulate some conclusions. First of all, it is apparent duality of the shadow economy in the reproduction process: a shadow economy affects regular reproduction process deforming its steps; under certain conditions, the shadow activity begins to reanimate economy (especially in times of crisis) stage of production, distribution, exchange and consumption. But if we look deeper, comes the second and most important thought - shadow economy doesn't just influence the economics, but through it other spheres of our lives, and, not surprisingly, in a bad way. 


\section{References}

Buehn A., Schneider F., 2012. Shadow Economies Around the World: Novel Insights,Accepted Knowledge, and New Estimates, International Tax and Public Finance, 19, 34-45.

Dreher A., Schneider F., 2009. Corruption and the Shadow Economy: An Empirical Analysis, Public Choice, 144/2, 67-78.

Enste D., Schneider F., 2006. Umfang und Entwicklung der Schattenwirtschaft in 145 Ländern, in: F. Schneider and D. Enste (eds.), Jahrbuch Schattenwirtschaft 2006/07. Zum Spannungsfeld von Poltik und Ökonomie, LIT Verlag, Berlin, 104-108.

Kramin, M. V., Safiullin, L. N., Kramin, T. V., \& Timiryasova, A. V. (2014). Drivers of economic growth and investment attractiveness of Russian regions. Life Science Journal, 11(6s).

Kramin, T. V., Ismagilova, G. N., \& Kramin, M. V. (2014). Assessment of Effect of Large Investment Projects on Development of Investment Potential of Regions of Russia as Exemplified by Universiade 2013 in Kazan1. Mediterranean Journal of Social Sciences, 5(18), 255.

Kramin, T. V., Safiullin, L. N., \& Timiryasova, A. V. (2014). Defining Priorities of Management of Investment Attractiveness of the Region and their Consideration in the Framework of Implementing Large Sports Events1. Mediterranean Journal of Social Sciences, 5(18), 275.

Kirshin I.A., Datsyk A.A., Titov A.V. Forecasting the Dynamics of an Innovative Cycle //World Applied Sciences Journal (Economics, Management and Finance). - 2013. - №27. - P. 197 - 201.

Kirshin I.A., Gareev B.R., 2013. Theory of constraints in value based cost management// World Applied Sciences Journal (Economics, Management and Finance), 27, pp.102-106.

Kucera, D., Roncolato L., 2008. Informal Employment: Two Contested Policy Issues// International Labor Review 147/3, pp. 57-69.

Report on Labor Market Situation, 2014, FSSS: www.gks.ru/wps/wcm/connect/rosstat_main/rosstat/ru/statistics/wages (Accessed on the 31st of August, 2014).

Schneider F., 2013. Shadow Economy in the Europe/l A.T.Kearney Working Paper, pp. 34-56.

Schneider, F., 2010. The Influence of Public Institutions on the Shadow Economy: An Empirical Investigation for OECD Countries// European Journal of Law and Economics ,6/3, pp. 45-70.

Schneider, F., 2011. Handbook on the Shadow Economy, Cheltenham (UK), Edward Elgar Publishing Company, pp. 68-70. 